\title{
АНТРОПОГЕНЕТИЧЕСКОЕ ИССЛЕДОВАНИЕ ПРОЦЕССОВ ВОСПРОИЗВОДСТВА ПОПУЛЯЦИИ ЭЛИСТЫ*
}

\begin{abstract}
В статье представлен анализ прочессов воспроизводства населения г. Элисты Республики Калмыкия 2007 г. Исследуется собранный репрезентативный популяционно-генетический материал с привлечением материалов переписей населения и других официальных статистических источников информации. В среднем в Элисте на каждую женщину пострепродуктивного возраста приходится 5.82 беременности, 2.15 рождений и 3.32 абортов. Исследование показало, что в городских семьях практикуется регулируемый тип рождаемости. Снижена пропориия спонтанных абортов, выкидышей и внематочных беременностей 0.28. Таким образом, только 37\% всех беременностей завериилась родами; соответственно 57\% беременностей искусственно прерывается. Применение метода J.F. Crow и его модификации позволили впервые количественно оченить вклад сочиальной компоненты в величину коэффициента отбора в популячии Элисты. Выявлено значительное возрастание вклада небиологических факторов в величину коэффициента максимально возможного потенциильного отбора.
\end{abstract}

Ключевые слова: популяция, антропогенетика, воспроизводство, дифференциальная плодовитость, дифференциальная смертность, коэффиџиент отбора

Ссылка при цитировании: Спиџына Н.X. , Балинова Н.B. Антропогенетическое исследование процессов воспроизводства популяции Элисты // Вестник антропологии. 2022, №1. С. 293-301.

DOI: $10.33876 / 2311-0546 / 2022-1 / 293-301$

(C) N.Kh. Spitsyna, N.V. Balinova

\section{ANTHROPOGENETIC STUDY OF REPRODUCTION PROCESSES IN ELISTA CITY POPULATION}

The article analyzes the processes of population reproduction in the city of Elista, the Republic of Kalmykia, in 2007. The collected representative population genetic material is investigated with the data from the All-Russia Census and other official statistical sources. On average, there are 5.82 pregnancies, 2.15 births

Спицына Наиля Хаджиевна - д.и.н., ведущий научный сотрудник Центра физической антропологии, Института этнологии и антропологии РАН (Москва, Ленинский пр. 32-а). Эл. почта: nailya47@mail.ru

Балинова Наталья Владимировна - с.н.с., к.б.н. ФБГНУ Медико-генетический научный центр имени академика Н.П. Бочкова (Москва, Москворечье, 1). Эл. почта: balinovs@mail.ru

* Работа выполнена при финансовой поддержке РФФИ, проект № 20-59-0012, Работа выполнена в рамках государственного задания Минобрнауки России для ФГБНУ МГНЦ 
and 3.32 abortions for every woman of post-reproductive age in Elista. The study demonstrates that birth control is practiced in urban families. The proportion of spontaneous abortions, miscarriages and ectopic pregnancies is as low as 0.28. Thus, only 37\% of all pregnancies resulted in livebirth; accordingly 57\% of pregnancies are terminated artificially. The contribution of the social component to the value of the natural selection coefficient in the population of Elista was calculated applying the method of J.F. Crow and its modifications. A significant increase in the contribution of non-biological factors to the value of the coefficient of the maximum possible potential selection was revealed.

Key words: population, anthropogenetics, reproduction, differential fertility, differential mortality, selection coefficient

For Citation: Spitsyna N.Kh., Balinova N.V. 2022. Anthropogenetic study of reproduction processes in Elista city population. Herald of Anthropology (Vestnik Antropologii) 1: 293-301.

Author Info: Spitsyna Nailya Kh. - PhD, DSc, Leading Research Scientist, Department of Anthropology, Federal state budgetary institution "Institute of ethnology and anthropology”, Russian Academy of Sciences (Moscow, RF). E-mail: nailya.47@mail.ru.

Balinova Nataliya V. - PhD, Senior Research Scientist, Federal state budgetary institution "Research Center for Medical Genetics" (Moscow, RF). E-mail: balinovs@mail.ru.

Funding: The work was carried out with the financial support of the RFBR, project No. 20-59-0012. The work was carried out within the framework of the state task of the Ministry of Education and Science of Russia for the FGBNU "MGNC".

\section{Введение}

Калмыки являются единственным монголоязычным народом в Юго-Восточной Европе. В основном они проживают на территории Республики Калмыкия в составе РФ. Население республики многонационально, наиболее многочисленными представителями других национальностей являются русские $(29,6 \%)$, даргинцы $(2,6 \%)$, чеченцы $(1,2 \%)$, казахи $(1,7 \%)$. Численность калмыков по данным переписи 2010 г. 162740 человек, что составляет 56,2\%. (Итоги Всероссийской переписи населения 2010 года в отношении демографических и социально-экономических характеристик отдельных национальностей).

Начиная с 90-х годов XX века, в России отмечаются резкие сдвиги в характере демографических процессов, основным проявлением которых является продолжающееся дальнейшее снижение рождаемости и рост смертности (Население и условия жизни в странах Содружества Независимых Государств 2002; Социально-экономическое положение России 2003; Иванов и др. 2003: 208). Репродуктивная структура популяций человека является универсальным индикатором социального и биологического состояния общества, реагирующим на любые происходящие эндогенные и экзогенные изменения (Курбатова 2014: 49). 
В ряду факторов, способствующих ее формированию, значительное место занимает биологическая компонента. Исследователями отмечаются такие тенденции, как снижение фертильности, рост патологии и осложнений в родах, пренатальной и постнатальной смертности, бесплодия в браках. Усиление искусственного контроля рождаемости в семьях и увеличение пропорции естественной убыли населения представляет серьезную проблему для будущих поколений (Санчат 1998: 24; Кулаков, Леонов 2000: 59-67; Курило 2009: 368; Гончарова и др. 2012: 35-40; Подзолкова и др. 2020: 120-131).

\section{Материалы и методы}

С целью изучения факторов, влияющих на процессы воспроизводства в городских популяциях РФ в процессе комплексных антропогенетических экспедиций, проводимых с 1992 года в Элисте, в 2007 году были собраны репрезентативные популяционно-генетические материалы, генетико-демографическая информация, определены репродуктивные и возрастные параметры. Сбор биодемографической информации проводился в группах женщин, завершивших индивидуальную репродукцию, по специально разработанной нами схеме на основе популяционно-генетического анкетирования (Пасеков, Ревазов 1975: 145-455). Составлены и проанализированы 460 бланков, вычислены индексы Кроу (Crow 1958: 1-13). Использованы материалы официальных источников информации Госкомстатата, материалы переписей, статистические материалы управлений здравоохранения.

\section{Основные результаты}

Антропогенетические исследования проведены в столице Республики Калмыкии Элисте. История возникновения города восходит к известному в 1865 г. небольшому селу Элиста Черноярского уезда Астраханской губернии, которое в 1918 г. стало центром Элистинского уезда. С 1930 года Элиста приобрела статус города (таблица 1).

Таблица 1

\section{Динамика численности населения города Элисты (Республика Калмыкия. Статистический ежегодник 2011)}

\begin{tabular}{|l|l|l|l|}
\hline годы & Численность населения & годы & Численность населения \\
\hline 1897 & 1200 & 2003 & 108327 \\
\hline 1931 & 7300 & 2004 & 107975 \\
\hline 1939 & 17100 & 2005 & 107508 \\
\hline 1959 & 23100 & 2006 & 107102 \\
\hline 1967 & 43000 & 2007 & 106730 \\
\hline 1970 & 49900 & 2008 & 106598 \\
\hline 1979 & 70300 & 2009 & 106730 \\
\hline 1989 & 89700 & 2010 & 106966 \\
\hline 2000 & 103000 & 2011 & 108009 \\
\hline
\end{tabular}


В 2007 г. отмечалось некоторое снижение численности до 106730 чел. Затем последовал рост и на 1 января 2011 г. численность населения Элисты составляла уже 108009 человек. Динамика роста численности населения г. Элисты, как и во всех городских популяциях РФ, обусловлена процессами воспроизводства и притока мигрантов (Курбатова, Победоносиева 2017: 1349-1359).

В 2007г. в Элисте достаточно высока доля лиц трудоспособного возраста. В популяции повышена пропорция женщин, наблюдается неравное соотношение полов (половой индекс равен 0.83) (таблица 2; рис.1).

Таблица 2

Динамика параметров демографической структуры г. Элисты

(Калмыкия в цифрах, 2007)

\begin{tabular}{l|l|l|l|l}
\hline $\begin{array}{l}\text { Возрастные } \\
\text { группы }\end{array}$ & $\mathbf{2 0 0 4}$ г. & $\mathbf{2 0 0 5}$ г. & $\mathbf{2 0 0 6}$ г. & $\mathbf{2 0 0 7}$ г. \\
\hline $\begin{array}{l}\text { Моложе трудоспособного } \\
\text { возраста }\end{array}$ & $21.49 \%$ & $20.78 \%$ & $20.30 \%$ & $19.94 \%$ \\
\hline Трудоспособного возраста & 64.53 & $64.97 \%$ & $65.45 \%$ & $65.50 \%$ \\
\hline $\begin{array}{l}\text { Старше } \\
\text { трудоспособного возраста }\end{array}$ & $13.98 \%$ & $14.16 \%$ & $14.25 \%$ & $14.56 \%$ \\
\hline Всего & 103777 чел. & 103449 чел & 103034 чел. & 1022748 чел. \\
\hline Половой индекс & 0.83 & & \\
\hline
\end{tabular}

\section{ПРОПОРЦИИ ВОЗРАСТНЫХ ГРУПП ЗАНЯТОСТИ НАСЕЛЕНИЯ Г.ЭЛИСТЫ 2007Г.}

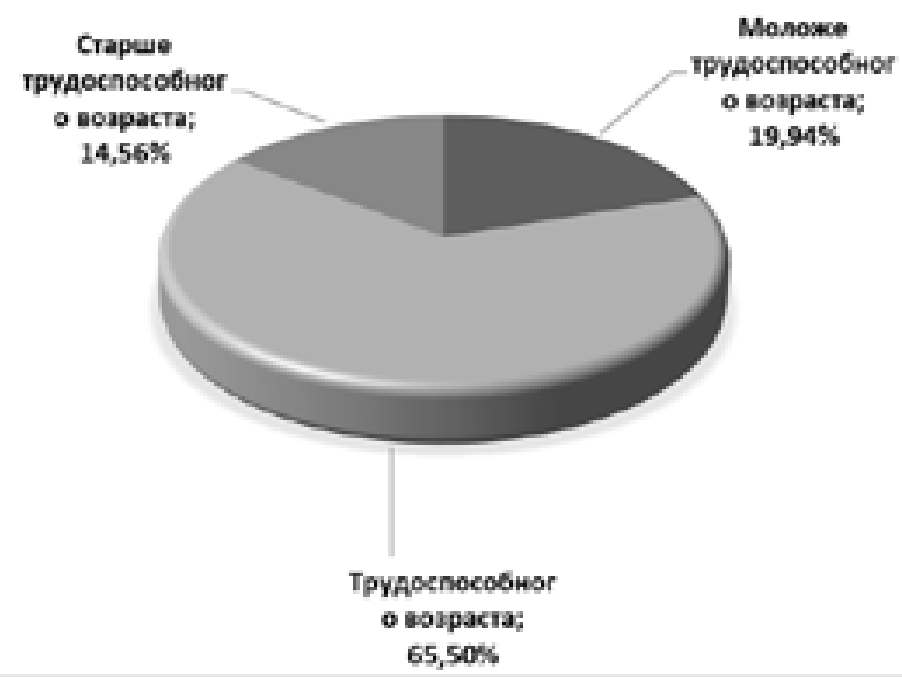


Обнаруживается выраженная диспропорция половозрастных групп, так резко снижена пропорция лиц дорепродуктивного возраста, которая составляет всего $26.30 \%$, соответственно индивидов репродуктивного возраста $43.90 \%$ и пострепродуктивного 29.80 \%. Естественный прирост населения в Элисте характеризуется положительной динамикой и с 2000 по 2006 гг. он составил: 1.8, 1.8, 1.8, 2.9, 3.3, 3.1, 4.0 соответственно. Что касается ситуации в Республике, то число родившихся превышает число умерших в Ики-Бирульском, Кетченеровском, Октябрьском, Целинном, Черноземельском, Яшалтинском, Яшкульском районах Калмыкии. Однако в ряде других районов республики: Городовиковском, Лаганском, Малодербетовском, Приютненском и Сарпинском, Юстинском районах во все указанные годы наблюдались отрицательные величины прироста населения. К числу возможных объяснений подобного неблагоприятного течения демографических процессов можно отнести влияние оттока молодежи в города и сопряженный с ним эффект постарения сельских популяций (Калмыкия в цифрах 2007).

В условиях изменившегося характера демографических процессов в последние годы представляет интерес оценка эффектов репродукции в популяции, проведенная в г. Элисте выборочном обследовании 460 женщин старше 45 лет (группа лиц завершивших индивидуальную репродукцию) (таблица 3).

Таблица 3

\section{Показатели репродуктивной функции пострепродуктивной возрастной когорты женщин популяции Элисты}

\begin{tabular}{l|l}
\hline Число обследованных женщин с завершенной репродукцией & $\begin{array}{l}\text { Популяция } \\
\text { Элисты } \\
\text { (N=460 человек) }\end{array}$ \\
\hline Среднее число беременностей, приходящееся на одну женщину & $5.8177 \pm 0.2853$ \\
\hline Среднее число родов, приходящееся на одну женщину & $2.1448 \pm 0.0211$ \\
\hline Среднее число детей, доживших до репродуктивного возраста & $2.1262 \pm 0.0067$ \\
\hline $\begin{array}{l}\text { Среднее число спонтанных абортов, внематочных беременностей, } \\
\text { выкидышей }\end{array}$ & $0.2757 \pm 0.0069$ \\
\hline Среднее число абортов & $3.3224 \pm 0.3761$ \\
\hline
\end{tabular}

В среднем на каждую женщину пострепродуктивной возрастной когорты приходится 5.8177 беременностей, 2.1448 рождений и 3.3224 абортов, и малая пропорция акушерской патологии беременностей 0.2757. В сравнительном аспекте женщина Элисты, завершившая индивидуальную репродукцию, имеет в среднем более высокое число доживших до репродукции детей $\left(\mathrm{X}_{\mathrm{s}}=2.126\right)$, чем в Саранске (1.6684), Казани (1.6862), Ставрополе (1.7612), Чебоксарах (1.8301). Следует отметить, что Элиста единственный город среди обследованных нами в этот период с расширенным типом воспроизводства, в Сыктывкаре наблюдалось простое воспроизводство, в остальных - суженный тип (Спищына 2006). В пострепродуктивной когорте женщин Элисты 37 \% всех беременностей завершилась родами; соответственно 57 \% беременностей искусственно прерывается, у женщин в Чебоксарах (59\%), в Казани (65.7 \%). 
Таблица 4

Индексы потенциального отбора $\left(\mathrm{I}_{\mathrm{T}}\right)$ и его компоненты в популяциях по методу Crow (1958), модификации Спицыной (2006)

\begin{tabular}{|c|c|c|c|c|c|c|c|c|}
\hline Популяции & $\mathbf{X}_{\mathrm{s}}$ & $\begin{array}{l}\text { Аборты } \\
(\%)\end{array}$ & $\mathbf{V}_{\mathrm{f}}$ & $\mathbf{P}_{\mathrm{s}}$ & $\mathbf{I}_{\mathrm{m}}$ & $\mathbf{I}_{\mathrm{f}}$ & $\begin{array}{l}\mathbf{I}_{\mathrm{T}} \\
\mathbf{I}_{\mathrm{T} 1}\end{array}$ & $\mathbf{I}_{\mathrm{T} 2}$ \\
\hline $\begin{array}{l}\text { г. Элиста } \\
1 \\
2\end{array}$ & $\begin{array}{l}2.1262 \\
2.1262\end{array}$ & $57 \%$ & $\begin{array}{l}1.9164 \\
1.9164\end{array}$ & $\begin{array}{l}0.8521 \\
0.3655\end{array}$ & $\begin{array}{l}0.1735 \\
1.7360\end{array}$ & $\begin{array}{l}0.4239 \\
0.4239\end{array}$ & $\begin{array}{l}0.6710 \\
1.9802\end{array}$ & 1.3092 \\
\hline $\begin{array}{l}\text { г. Казань } \\
1 \\
11\end{array}$ & $\begin{array}{l}1.6862 \\
1.6862\end{array}$ & 65.7 & $\begin{array}{l}0.9622 \\
0.9622\end{array}$ & $\begin{array}{l}0.9016 \\
0.3163\end{array}$ & $\begin{array}{l}0.1091 \\
2.1615\end{array}$ & $\begin{array}{l}0.3384 \\
0.3384\end{array}$ & $\begin{array}{l}0.4844 \\
3.2243\end{array}$ & 2.7399 \\
\hline $\begin{array}{l}\text { г. Чебоксары } \\
1 \\
2\end{array}$ & $\begin{array}{l}1.8301 \\
1.8301\end{array}$ & 59.6 & $\begin{array}{l}1.1934 \\
1.1934\end{array}$ & $\begin{array}{l}0.7871 \\
0.3138\end{array}$ & $\begin{array}{l}0.2705 \\
2.1446\end{array}$ & $\begin{array}{l}0.3563 \\
0.3563\end{array}$ & $\begin{array}{l}0.7232 \\
3.2650\end{array}$ & 2.5418 \\
\hline $\begin{array}{l}\text { г. Саранск } \\
1 \\
2\end{array}$ & $\begin{array}{l}1.6684 \\
1.6684\end{array}$ & 54.0 & $\begin{array}{l}0.8154 \\
0.8154\end{array}$ & $\begin{array}{l}0.7271 \\
0.3369\end{array}$ & $\begin{array}{l}0.3753 \\
1.9682\end{array}$ & $\begin{array}{l}0.2929 \\
0.2929\end{array}$ & $\begin{array}{l}0.7781 \\
2.8376\end{array}$ & 2.0595 \\
\hline $\begin{array}{l}\text { г. Ставро- } \\
\text { поль } \\
1 \\
2\end{array}$ & $\begin{array}{l}1.7612 \\
1.7612\end{array}$ & 65.9 & $\begin{array}{l}1.0179 \\
1.0179\end{array}$ & $\begin{array}{l}0.8762 \\
0.2980\end{array}$ & $\begin{array}{l}0.1413 \\
2.3557\end{array}$ & $\begin{array}{l}0.3282 \\
0.3282\end{array}$ & $\begin{array}{l}0.5158 \\
3.4570\end{array}$ & 2.9412 \\
\hline $\begin{array}{l}\text { г. Сыктыв- } \\
\text { кар } \\
1 \\
2\end{array}$ & $\begin{array}{l}2.1964 \\
2.1964\end{array}$ & 39.0 & $\begin{array}{l}1.0698 \\
1.0698\end{array}$ & $\begin{array}{l}0.7785 \\
0.4768\end{array}$ & $\begin{array}{l}0.2845 \\
1.0973\end{array}$ & $\begin{array}{l}0.2217 \\
0.2217\end{array}$ & $\begin{array}{l}0.5693 \\
1.5623\end{array}$ & 0.9930 \\
\hline
\end{tabular}

Примечание:

$\mathrm{X}_{\mathrm{s}}$ - среднее число детей, приходящееся на одну женщину

пострепродуктивного возраста ;

$\mathrm{V}_{\mathrm{f}}$ - дисперсия среднего числа детей;

$\mathrm{P}_{\mathrm{s}}$ - доля потомков, доживших до репродуктивного возраста;

$\mathrm{I}_{\mathrm{f}}$ - компонента дифференциальной плодовитости;

$\mathrm{I}_{\mathrm{T}}$ - индекс потенциального отбора (без включения в анализ числа беременностей, завершившихся абортом);

$\mathrm{I}_{\mathrm{T1}}$ - вариант расчета с включением в анализ числа беременностей,

завершившихся абортом.

$\mathrm{I}_{\mathrm{T} 2}{ }^{-}$мера социальной регуляции репродукции

Применение модификации метода J.F. Crow для расчета индексов потенциального отбора позволила количественно оценить вклад социальной компоненты в величину коэффициента максимально возможного потенциального отбора в популяциях (Спицына, 2006: 126-139). Это стало возможным только в связи с особенностями репродукции в популяциях нашей страны. Большое среднее число беременностей и малая пропорция детей, приходящихся на одну женщину, свидетельствуют о мерах по регуляции рождаемости, проводимых в основном с помощью искусственно- 
го прерывания беременностей. В пострепродуктивных когортах женщин отчетливо выявляется сопряженность силы социальной регуляции репродукции с пропорцией абортов. Данная особенность, выраженная и в городах и селах, о слабом развитии практики применении контрацептивов.

Применение метода позволило наиболее полно учитывать действие одного из основных систематических факторов эволюции в популяциях (таблица 4).

Исследование индексов потенциального отбора в городских популяциях выявило резкое возрастание вклада небиологических факторов в величину коэффициента отбора: в г. Ставрополе сила социального прессинга равна 2.9412, Казани - 2.7399, Чебоксарах - 2.5418, Саранске - 2.0595, Сыктывкаре - 0.9930, Элисте - 1.3092. Количественное выражение возросшего социального регулирования рождаемости имеет определенную корреляцию с численностью населения городов, исключение составляет Ставрополь (с самым высоким значением коэффициента при меньшей численности, чем в Казани), и Сыктывкар (численность выше, чем в Элисте, а социальный прессинг немного ниже).

Известно, что планирование размеров семьи нивелирует различия индивидов в отборе на плодовитость. Однако, выявленные факты снижения акушерской патологии в группах с высокой степенью социального воздействия на репродуктивные процессы позволили нам определить двоякий эффект планирования размеров потомства на воспроизводство в популяциях: с одной стороны, он нивелирует индивидуальные различия в отборе на плодовитость; с другой - снижает пропорцию пренатальной патологии в популяциях (таблица 5).

Таблица 5

\section{Сравнительные данные по уровню акушерской патологии и индекса социального регулирования $\mathrm{I}_{\mathrm{T} 2}$ В популяциях}

\begin{tabular}{l|l|l|l}
\hline Популяции & Пропорция акушерской патологии & Аборты (\%) & $\mathbf{I}_{\mathbf{T 2}}$ \\
\hline Элиста & 0.27 & $57.0 \%$ & 1.3092 \\
\hline Ставрополь & 0.20 & $65.9 \%$ & 2.9412 \\
\hline Саранск & 0.57 & $54.0 \%$ & 2.0595 \\
\hline Чебоксары & 0.44 & $59.6 \%$ & 2.5418 \\
\hline Казань & 0.22 & $65.7 \%$ & 2.7399 \\
\hline Сыктывкар & 0.50 & $39.0 \%$ & 0.9930 \\
\hline
\end{tabular}

Как видно из данных табл. 5, семьи Элисты являются исключением, в них малая пропорция акушерской патологии сочетается с относительно низкой величиной коэффициента социального регулирования репродукции в ряду исследованных нами городских популяций.

\section{Заключение}

Результаты антропогенетического исследования особенностей процессов воспроизводства популяции Элисты позволили сделать следующие заключения. 
Анализ пострепродуктивной возрастной когорты женщин Элисты в целом характеризует демографическую ситуацию предшествующего поколения как положительную.

Индекс Кроу и основные статистические данные витальности указывают на возрастание влияния небиологических факторов на процессы воспроизводства в популяции.

\section{Научная литература}

Гончарова Н.Н., Мартышкина Е.Ю., Казначеева Т.В., Арсланян К.Н., Адамян Л.В., Курило Л.Ф., Сорокина Т.М., Черных В.Б. Медико-генетические аспекты бесплодия // Акушерство, гинекология, репродукция, 2012. т. 6, № 2, С. 35-40.

Иванов В.П., Чурносов М.И., Кожухов М.А., Пахомов С.П., Королев В.А. Популяционно-демографические и экологические аспекты репродуктивного здоровья в Центральном Черноземье. Курск: КГМУ, 2003. 208 с.

Итоги Всероссийской переписи населения 2010 года в отношении демографических и социально-экономических характеристик отдельных наџиональностей http://www.gks.ru/ free_doc/new_site/perepis2010/croc/results2.html Дата обращения 08.11.2021.

Калмыкия в циифрах 2007 г. Ежегодник Госкомстата РК. Элиста: Калмыкиястат, 2008. 216 С.

Кулаков В.И., Леонов А.А. Экстракорпоральное оплодотворение и его новые направления в лечении женского и мужского бесплодия. М.: МИА. 2000. 59-67.

Курбатова О. Л., Победоносиева Е. Ю. Изменчивость параметров естественного воспроизводства и индексов Кроу в этнических группах двух крупнейших мегаполисов России // Генетика. 2017. Т. 53. № 11. С. 1349-1359.

Курбатова О.Л. Демографическая генетика городского населения: Автореферат дисс. доктора биол. наук. М., 2014, 49 с.

Курило Л.Ф. Являются ли репродуктивные технологии, технологии стволовых клеток и клонирования человека нашим будущим? Будущее жизни и будущее нашей цивилизации. М.: ЗАО «Кудесники». 2009. 368 С.

Население и условия жизни в странах Содружества Независимых Государств: Стат. сб./ Межгос. стат. Комитет СНГ. М., 2002.

Пасеков В.П., Ревазов А.А. К популяционной генетике населения Европейского Севера СССР. Сообщение 1. Данные по структуре шести деревень Архангельской области // Генетика. 1975 , т. 2, №7, c. $145-455$.

Подзолкова Н.М., Сквориова М.Ю., Прилуикая С.Г. Беременность после ЭКО // Проблемы репродукции, 2020. 26(2) б 120-131.

Республика Калмыкия. Статистический ежегодник.2011. Элиста: Калмыкиястат, 2011. 321 с.

Санчат Н.О. Популяционно-генетическое изучение народонаселения республики Тува. Автореф., канд. дисс. Томск, 1998. 24 С.

Социально-экономическое положение России. М.: Госкомстат РФ, 2003.

Спицына H.X. Демографический переход в России. Антропогенетический анализ. М.: Наука, 2006. $311 \mathrm{C}$.

Crow J.F. Some possibilities for measuring selection intensities in man // Human Biol., 1958, 30. P. 1-13.

\section{References}

Crow J.F. Some possibilities for measuring selection intensities in man // Human Biol., 1958. 30: 1-13. Goncharova, N.N., E.Iu. Martyshkina, T.V. Kaznacheeva, K.N. Arslanian, L.V Adamian., L.F. Kurilo,

T.M. Corokina, and V.B. Chernykh. 2012. Mediko-geneticheskie aspekty besplodiia [Medical and genetic aspects of infertility] // Akusherstvo, ginekologiia, reproduktsiia, 6 (2): 35-40. 
Ivanov, V.P., M.I. Churnosov, M.A. Kozhukhov, S.P. Pakhomov, and V.A., Korolev 2003. Populiatsionno-demograficheskie $i$ ekologicheskie aspekty reproduktivnogo zdorov'ia $v$ Tsentral'nom Chernozem'e [Population and Demographic and Environmental Aspects of Reproductive Health in Central Chernozem Region]. Kursk: KGMU. 208 p.

Itogi Vserossiiskoi perepisi naseleniia 2010 goda v otnoshenii demograficheskikh i sotsial'noekonomicheskikh kharakteristik otdel'nykh natsional'nostei [Results of the 2010 All-Russian Population Census with regard to the demographic and socio-economic characteristics of certain nationalities] http://www.gks.ru/free_doc/new_site/perepis2010/croc/results2.html Data obrashcheniia 08.11.2021.

Kalmykiia v tsifrakh. 2007. Ezhegodnik Goskomstata RK [Kalmykia in Figures 2007. Yearbook of the State Statistics Committee of the RK]. Elista, 2008. 216 p.

Kulakov, V.I., and A.A. Leonov 2000. Ekstrakorporal'noe oplodotvorenie i ego novye napravleniia $v$ lechenii zhenskogo i muzhskogo besplodiia [In vitro fertilization and its new directions in the treatment of female and male infertility]. Moscow: MIA: 59-67.

Kurbatova, O. L., and E. IU. Pobedonostseva. 2017. Izmenchivost' parametrov estestvennogo vosproizvodstva $\mathrm{i}$ indeksov Krou $\mathrm{v}$ ètnicheskikh gruppakh dvukh krupnershikh megapolisov Rossii [Variability of the parameters of natural reproduction and Crow indices in the ethnic groups of the two largest megacities of Russia]// Russian Journal of Genetics. 53 (11): 1349-1359.

Kurbatova, O.L. 2014. Demograficheskaia genetika gorodskogo naseleniia [Demographic genetics of the urban population]: Avtoreferat diss. doktora biol. nauk. Moscow. 49 p.

Kurilo, L.F. 2009. Iavliaiutsia li reproduktivnye tekhnologii, tekhnologii stvolovykh kletok $i$ klonirovaniia cheloveka nashim budushchim? Budushchee zhizni $i$ budushchee nashei tsivilizatsii [Are reproductive technology, stem cell technology, and human cloning our future? The future of life and the future of our civilization]. Moscow: ZAO "Kudesniki': $368 \mathrm{p}$.

Naselenie $i$ usloviia zhizni $v$ stranakh Sodruzhestva Nezavisimykh Gosudarstv. 2002 [Population and Living Conditions in the Countries of the Commonwealth of Independent States]. Stat. sb./ Moscow : Mezhgos. stat. Komitet SNG.

Pasekov, V.P., and A.A. Revazov 1975. K populiatsionnoi genetike naseleniia Evropeiskogo Severa SSSR. Soobshchenie 1. Dannye po strukture shesti dereven' Arkhangel'skoi oblasti [Population genetics of the population of the European North of the USSR. Report 1. Data on the structure of six villages in the Arkhangelsk region] // Russian Journal of Genetics 2 (7): 145-455.

Podzolkova, N.M., M.Iu. Skvortsova, and S.G. Prilutskaia 2020. Beremennost' posle EKO [Pregnancy after IVF] // Problemy reproduktsii. 26(2) b: 120-131.

Respublika Kalmykiia. Statisticheskii ezhegodnik. 2011 [Republic of Kalmykia. Statistical Yearbook]. Stat.sb./ Elista: Kalmykiiastat. 321 p.

Sanchat, N.O. Populiatsionno-geneticheskoe izuchenie narodonaseleniia respubliki Tuva. 1998. [Population Genetic Study of the Population of the Republic of Tuva]. Avtoref., kand. diss. Tomsk.. 24 p.

Sotsial'no-ekonomicheskoe polozhenie Rossii'. 2003. [Socio-economic situation in Russia]. Moscow: Goskomstat RF.

Spitsyna, N.Kh. 2006. Demograficheskii perekhod v Rossii. Antropogeneticheskii analiz [Demographic transition in Russia. Anthropogenetic Analysis]. Moscow: Nauka,. 311 p. 